\title{
Development and validation of a prototype application on breastfeeding for health professionals*
}

\author{
Desenvolvimento e validação de protótipo de aplicativo sobre aleitamento \\ materno para profissionais de saúde \\ Desarrollo y validación de un prototipo de aplicación sobre la lactancia \\ materna para los profesionales de la salud
}

How to cite this article:

Guimarães CMS, Fonseca LMM, Monteiro JCS. Development and validation of a prototype application on breastfeeding for health professionals. Rev EsC Enferm USP. 2021;55:e20200329. doi: https://doi.org/10.1590/1980-220X-REEUSP-2020-0329

\section{Carolina Maria de Sá Guimarães ${ }^{1}$ \\ Luciana Mara Monti Fonseca² \\ Juliana Cristina dos Santos Monteiro²}

* Extracted from the thesis: "Desenvolvimento e validação de um protótipo de aplicativo móvel sobre aleitamento materno para profissionais de saúde", Universidade de São Paulo, Escola de Enfermagem de Ribeirão Preto, Programa de Pós-Graduação Enfermagem em Saúde Pública, 2019

${ }^{1}$ Universidade de São Paulo, Escola de Enfermagem de Ribeirão Preto, Programa de Pós-Graduação Enfermagem em Saúde Pública, SP, Brazil.

${ }^{2}$ Universidade de São Paulo, Escola de Enfermagem de Ribeirão Preto, Departamento de Enfermagem Materno-infantil e Saúde Pública, Ribeirão Preto, Ribeirão Preto, SP, Brazil.

\section{ABSTRACT}

Objective: To develop and validate a prototype mobile application on breastfeeding for health professionals. Method: Methodological study. To build this prototype, information obtained from interviews with six health professionals who were certified as international breastfeeding consultants was employed. For validating the prototype, screenshots were sent to each professional participating in the first phase, as well as an adapted instrument to assess appearance, content, and language. Results: Most assessments were "great" or "good". The participating professionals have also made important considerations for content enhancement, mainly for the clinical content. Conclusion: The prototype was positively assessed by the professionals, fulfilling the proposed objective. This study is highly important for breastfeeding care professional practice, since it presents a tool which improves quality of care by contributing to the best evidence-based practice.

\section{DESCRIPTORS}

Breast Feeding; Wireless Technology; Telemedicine; Women's Health; Maternal and Child Health; Information Technology. 


\section{INTRODUCTION}

Breastfeeding is considered the gold standard of child nutrition and its benefits are widely described in the literature ${ }^{(1)}$.

In spite of the benefits, most women are still unable to exclusively breastfeed their babies up to six months of life, following the recommendation of the World Health Organization (WHO) and the Brazilian Ministry of Health $(\mathrm{MH})^{(2)}$, particularly in Brazil, where those indexes are still lower than the recommended. Women's confidence on their breastfeeding ability is one of the factors that may interfere in the process of breastfeeding, being positively influenced by appropriate professional support, since health professional guidance is considered to be one of the pillars to build and maintain maternal self-efficacy during breastfeeding ${ }^{(3)}$.

Health professional support to women is fundamental in the first weeks from birth, when they face most of the challenges and difficulties to breastfeeding, increasing the risk of early weaning, in addition to being important for the maintenance and support to continuous breastfeeding ${ }^{(4)}$. Clinical practice regarding breastfeeding generally requires health professionals to have specific knowledge based on updated scientific evidence, enhancing their knowledge and skills and providing support to an appropriate clinical reasoning $^{(5-6)}$. In spite of that, knowledge and skills gaps in breastfeeding support have been reported in all care levels and described in the scientific literature, damaging quality of care both to women and their children and increasing the risk of complication and early weaning ${ }^{(4,7)}$.

Technological innovation in the health area enables professionals, mainly nurses, to achieve excellent care levels, possibly positively impacting different areas of knowledge. These innovations must be integrated to the care process, working as a support to data collection, decision-making, and knowledge production ${ }^{(8)}$. In the last decades a growth in the use of mobile technology, known as mhealth, with wireless internet connection, has been observed worldwide.

Mobile technology benefits health professionals, promoting access to continuous education, improving their technical abilities through easy access to online courses, for example, and providing for the obtention of more information to establish health diagnosis and refer clients to appropriate treatment ${ }^{(9)}$. In relation to mother and child health, mobile technology, through applications, known as apps, may facilitate the access to health services and enable consultation and information exchange among professionals in this area and other health professionals, improving care support and increasing social connectivity ${ }^{(10)}$.

Using mobile applications to support breastfeeding may be an important tool for health professionals when considering the previously described benefits, such as facilitating communication with women in the postpartum period, favoring the access to online contents and training to improve technical skills and provide constant updating. In spite of that, the literature demonstrates that most apps are developed to be used within families and no app developed for professional use during breastfeeding care as a tool for consulting or registering information on the provided care was identified. A variety of available applications for smartphones is found on digital stores, but most were not developed based on scientific evidence and was not assessed for their efficacy ${ }^{(11)}$. A study which analyzed apps on breastfeeding available in Portuguese for the Brazilian context identified that most applications had information that was not in agreement with official recommendations, such as the use of chronometers to register breastfeeding duration, contradicting the recommendation of free demand, which may provide conflicting information for families if this time analysis is not in conjunction with an appropriate professional assessment, since quality of breastfeeding is not directly related to its duration, but also to other factors, such as weight gain ${ }^{(12)}$.

The identification of gaps in the development of applications related to breastfeeding justifies this study, which aims to help professionals in their practice with women, their children, and their families during the process of breastfeeding, with reliable information based on scientific evidence, favoring a more efficient and effective performance which may contribute to an increase in breastfeeding rates in Brazil. Thus, this research had the objective of developing a prototype mobile application on breastfeeding for health professionals.

\section{METHOD}

\section{Design of Study}

This is a methodological study based on the fundamental items for software creation following the steps of Pressman's Prototyping model ${ }^{(13)}$ and the fundaments of Health Communication for content development.

\section{Development Phases}

The first step consisted of forming a development team composed of health professionals who provided care to women and their babies during breastfeeding with the objective of identifying their needs during performance and the type of function which might be useful to compose the prototype application. The team selection was by convenience, searching for professionals in different regions of Brazil with the objective of a forming multiprofessional team of experts based on the following inclusion criteria: high education in the health area, being certified by the IBLCE (International Board of Lactation Consultant Examiners) and providing breastfeeding care to women and their children in their daily work. The IBLCE is an independent international organ which has been working for more than 30 years, establishing high quality standards in breastfeeding care worldwide and certifies professionals who have reached these excellence standards as "International Board Certified Lactation Consultant" (IBCLC) ${ }^{(14)}$. The professionals invited to participate in the study amounted to 13 , out of which 06 accepted the invitation (01 obstetric and neonatal nurse, 01 nutritionist, 01 pharmacist, 01 speech therapist, 01 pediatrician, and 01 gynecologist and obstetrician). 
The professionals were identified on the website of the International Lactation Consultant Association (ILCA), which includes a database with all professionals certified by IBLCE worldwide ${ }^{(15)}$, and on a smartphone application group for exchanging messages (WhatsApp ${ }^{\circledR}$ ) with certified Brazilian consultants providing care in Brazil or in other countries, contacted through electronic mail through which they have received an invitation letter to participate in the study. Both platforms were used to confirm contact information and facilitate communication with the professionals. After accepting participation, the professionals received the Informed Consent Form (ICF) to print, sign, and send it back through electronic mail or conventional mail to the main researcher. After the ICF was signed, each professional was individually interviewed in a pre-scheduled moment through video conference $\left(\right.$ Skype $\left.^{\circledR}\right)$ or video call using the application WhatsApp ${ }^{\circledast}$. The interviews took place from July to September 2018 and were recorded using the program Apowersoft Audio Recorder ${ }^{\circledR}$, with a mean duration of 30 minutes each.

An instrument which was specially created for this study for sociodemographic data collection was used in the interviews. This instrument's variables were name, age, education, time since graduation, times since IBCLC certification, time working with breastfeeding, workplace, and municipality/state of workplace. After sociodemographic data collection, a semi-structured script with six open-ended guiding questions was used, promoting a better knowledge of the routines of professionals and their needs.

Each participant's sociodemographic data were stored in an electronic spreadsheet structured in Microsoft Excel $^{\circledR}$, with double typing to eliminate possible errors and guarantee the reliability of the collected data. For an analysis of the sociodemographic variables, data analysis based on descriptive statistics was performed using absolute and relative frequency for qualitative variables and means and medians for quantitative variables. The analysis of the interviews enabled the construction of the "quick project" of the prototype through organization of the content and of the functions that would be present in the app, facilitating a wider visualization of the disposition of each item in the app screens and the information which would need to be searched for and added to complement what was thought of by the development team.

The prototype was then drawn on paper, i.e., the graphical elaboration of the screens and their interactions in relation to language, design, and functionalities from the quick project elaborated in the previous phase. The clinical content referring to clinical management of breastfeeding was also elaborated, distributing it on the screens according to the theme and considering the following topics for each theme: definition, signs and symptoms, risk factors, treatment, and employed references. The prototype screens were elaborated using the website canva.com, a free graphic design website. Through this website, the creation of a logo for the prototype was also made possible, which granted it more personality.

\section{Prototype Validation}

After the screens were created, each member of the development team received a message through electronic mail explaining the procedure for content validation, error detection, and necessary changes. The content of the prototype was also sent in PDF files for validation with a Non-disclosure Agreement, which should be signed and returned with the material's assessment. The overall content was assessed by all team members and each topic of the specific content referring to the item "Clinical Protocols" was assessed by 02 development team members. This division was opted for due to the volume of data to be analyzed for each participant. The distribution of themes to each professional was made through a simple random selection. The validation phase was performed from May to June 2019.

For this validation phase, the instrument used by Fonseca et al. ${ }^{(16)}$ was adapted and the authorization for use and adaptation of the instrument was obtained through electronic mail. This instrument assesses aesthetic and visual aspects as well as content and is constituted of a Likert-type scale with five response options for each question, which are: Terrible (1), Bad (2), Average (3), Good (4), and Great (5). Each assessed item was considered appropriate when 70\% or more of the consultants attributed the concepts good or great to the assessed aspect ${ }^{(16)}$. The instrument was divided into 03 parts: "general content" (presentation screens, login, main screen, and general menu), in which visual and colors, coherence between content and target public, language, content distribution, font size and style, and images were assessed; "My follow-ups" analyzing language, content, possibility of use of the application in different care contexts, suggested functions; "Clinical Protocols", with the assessment of theme relevance, content, language, nomenclature, illustrations, topic sequence, contribution to clinical reasoning, font size, visual, and colors. In each of those three parts, a field was also left for "comments", in which consultants were oriented to freely express their opinions, with criticism and suggestions to improve the prototype even more. After the adaptation of the assessment items, the instrument was inserted into the Google Forms ${ }^{\circledR}$ platform and the link was sent to the professionals with the material for validation.

\section{Ethical Aspects}

This study was approved by the Research Ethics Committee (REC) of the School of Nursing of Ribeirão Preto of Universidade de São Paulo (EERP-USP) on opinion n. 1.780.874, dated October 19, 2016, and abides by the National Health Council's resolution n. 466/2012.

\section{RESULTS}

The development team was formed by six health professionals, all female, with one obstetric and neonatal nurse, one nutritionist, one pharmacist, one speech therapist, one pediatrician, and one gynecologist and obstetrician. The mean age of the professionals was 44.7 years. Three professionals (50\%) had 10 to 20 years from graduation 
and four (66.67\%) had less than 10 years of certification. Concerning time providing breastfeeding care, half the professionals (50\%) had been working for less than 10 years in this practice and one (16.67\%) had been providing breastfeeding support for over 20 years. Concerning workplace, three (50.0\%) worked at a Human Milk Bank, three $(50.0 \%)$ at a private clinic, two $(33.33 \%)$ performed domiciliary postpartum care, and one (16.67\%) worked at a maternity ward. Out of the total of professionals, four (66.67\%) worked at more than one workplace. Regarding the municipality of work, three $(50 \%)$ are located in the state of São Paulo (Campinas, São Bernardo do Campo, and São Paulo).

From the points which were emphasized in the interviews, the functionalities were related to the contents referring to breastfeeding management which might be useful to health professionals in their clinical practice in any care breastfeeding care context. The selected content is presented in Figure 1. With the content ready, the last part of this phase was to name the prototype. The name was chosen with the objective of representing the theme of this prototype, being easily identifiable in virtual stores, and referring somehow to its target public. Thus, the prototype was named "Amamentação Prô" (Portuguese for "Breastfeeding Pro").

The next step was the construction of the screens from the raised themes. An opening screen with name and logo was created, as well as the user registration screen, login and password screen, and main screen (Figure 2). Subsequently, the screen of the "General Menu" was created, presenting all the functionalities of the prototype, "My follow-ups", and "Clinical Protocols" (Figure 3).

With a prototype elaborated, the development team members received the material for validation. In this phase, 01 member did not return the validation and its content was redistributed among the others.

\begin{tabular}{|l|}
\hline User registration \\
\hline - Name; \\
- Education; \\
- Location; \\
- Professional area; \\
- Working with \\
clinical case \\
supervision; \\
- Contacts \\
(telephone and e- \\
mail); \\
- Login \\
- Password \\
\hline
\end{tabular}

\begin{tabular}{|l|}
\hline $\begin{array}{c}\text { General Content } \\
\text { (functions) }\end{array}$ \\
- My account \\
- My follow-ups \\
- Next \\
consultations \\
- Clinical protocols \\
- Medication and \\
breastfeeding \\
- News and articles \\
- Related websites \\
- Amamentação Pró \\
Network \\
- Events \\
\hline
\end{tabular}

\section{Theoretical content (clinical protocols)}

\section{- Inappropriate weight gain;}

- Breast candidiasisis;

- Raynaud's phenomenon;

- Hypogalactia;

- Breast engorgement;

- Mastitis;

- Nipple lesions;

Figure 1 - Prototype's quick project content.

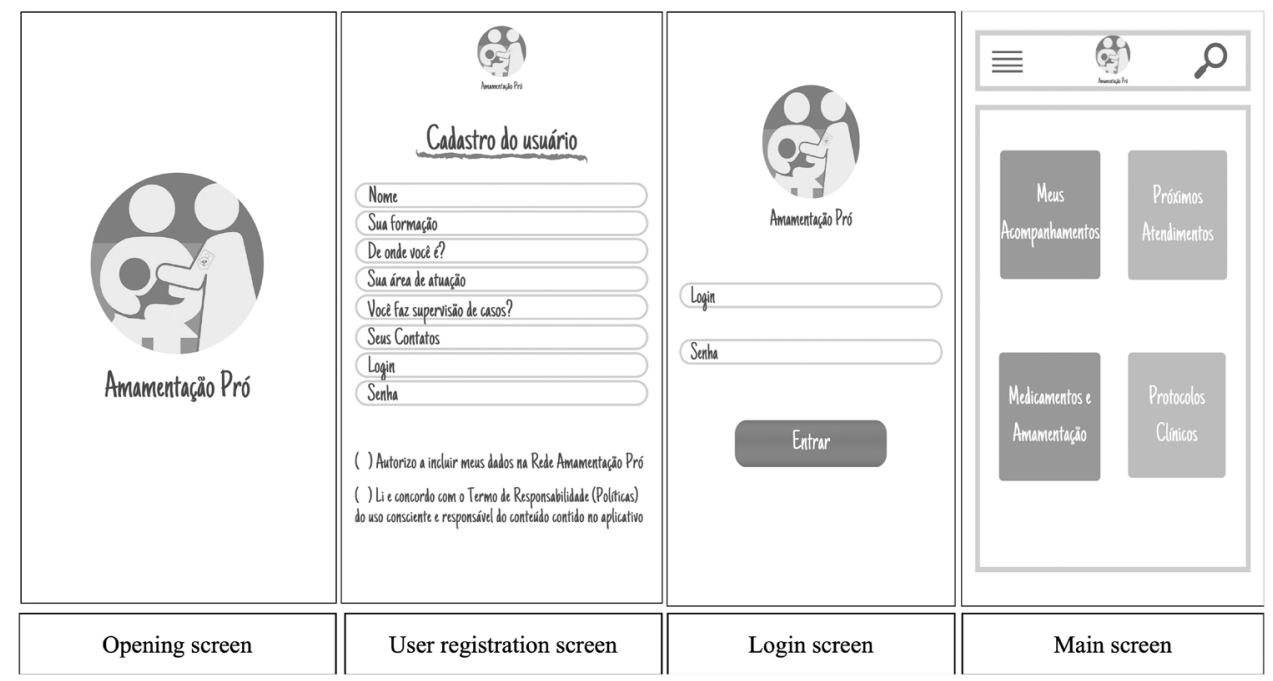

Figure 2 - Opening screens, user registration, login and password, and main screen of the prototype of Amamentação Pró. 


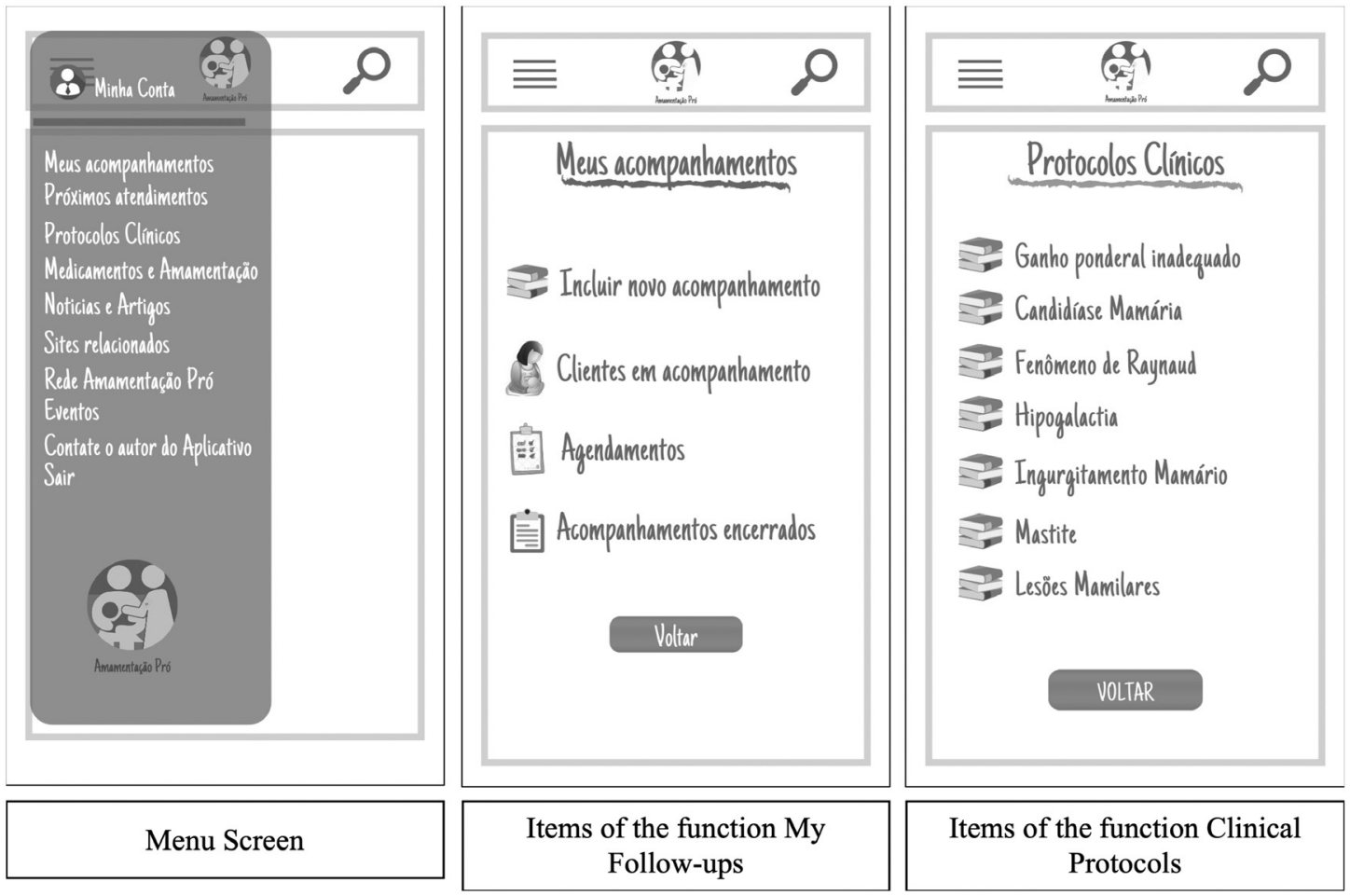

Figure 3 - General menu screen, "My Follow-ups" and "Clinical Protocols" of the "Amamentação Pró" prototype.

In the assessment of the topic "General Content", $80 \%$ of the consultants attributed the concepts "great" or "good" to visual and colors and $60 \%$ of the consultants considered the content as "great" for its target public. Concerning language, four $(80 \%)$ considered it as "great" or "good" and three (60\%) attributed "great" to content distribution. Concerning font size, most (60\%) attributed the concept "great" or "good", $60 \%$ considered the font style "good" and three $(60 \%)$ of the consultants assessed the illustrations used for each item as "great".

Concerning the topic "My Follow-ups", 80\% of the consultants attributed the concept "great" or "good" to language as well as for content (80\%) and suggested functions (80\%). Referring to the possibility of using the app in other care contexts, four of the consultants (80\%) considered this item as "great". The answers to this topic are presented in Table 1. In the comments, the consultants highlighted the importance of using more technical language, since the application is directed at health professionals and is supposed to be quickly filled. They also suggested adding to the care form fields for "name of the baby", "main complaint", and "delivery complications". The consultants also suggested a list of parameterized problems (or ICD) so as to facilitate the search for patients with a particular alteration. There was also an observation that suggested a field to annotate complications of both mother and baby during childbirth.

Two of the items assessed in the topic "General Content" received the concepts "great" or "good" from $60 \%$ of the consultants. Despite being lower than the $70 \%$ indicated by Fonseca et al. (2008), the result was considered positive since most consultants attributed such concepts. Three consultants suggested increasing font size to facilitate reading.
Table 1 - Assessment of consultants on the topic "General Content" and "My Follow-up" of the prototype of the application Amamentação Pró - Ribeirao Preto, SP, Brazil, 2019.

\begin{tabular}{|c|c|c|c|c|c|c|}
\hline \multirow{2}{*}{ Assessed aspects } & \multicolumn{5}{|c|}{ Consultants ${ }^{\prime}$ answers $(n=5)$} & \multirow{2}{*}{ Tota } \\
\hline & Terrible & Bad & Average & Good & Great & \\
\hline \multicolumn{7}{|l|}{ General content } \\
\hline $\begin{array}{l}\text { Visual and } \\
\text { colors }\end{array}$ & 00 & 00 & 01 & 02 & 02 & 05 \\
\hline $\begin{array}{l}\text { Adequacy to } \\
\text { target public }\end{array}$ & 00 & 00 & 02 & 00 & 03 & 05 \\
\hline Language & 00 & 00 & 01 & 01 & 03 & 05 \\
\hline $\begin{array}{l}\text { Content } \\
\text { distribution }\end{array}$ & 00 & 00 & 00 & 02 & 03 & 05 \\
\hline Font size & 00 & 00 & 02 & 02 & 01 & 05 \\
\hline Font style & 00 & 00 & 01 & 03 & 01 & 05 \\
\hline Item illustration & 00 & 00 & 00 & 02 & 03 & 05 \\
\hline \multicolumn{7}{|l|}{ My Follow-ups } \\
\hline Language & 00 & 00 & 00 & 02 & 03 & 05 \\
\hline Content & 00 & 00 & 01 & 01 & 03 & 05 \\
\hline $\begin{array}{l}\text { Possibility of } \\
\text { using the app } \\
\text { in other care } \\
\text { contexts }\end{array}$ & 00 & 00 & 01 & 01 & 03 & 05 \\
\hline $\begin{array}{l}\text { Suggested } \\
\text { functions }\end{array}$ & 00 & 00 & 00 & 01 & 04 & 05 \\
\hline
\end{tabular}

Source: Elaborated by the authors, 2019.

The clinical protocols were about the themes "low maternal milk production", "inappropriate weight gain", "breast candidiasis", "Raynaud's Phenomenon", "breast engorgement", "mastitis", and "nipple lesions". Each Clinical 
Protocol contained the definition of complication, signs, and symptoms, causes and/or or risk factors, treatments, and references, contemplating the clinical management of situations which caused difficulties such as latching and suction, appropriate position, among other factors related to the newborn's behavior. Thus, in that moment, a specific protocol for the newborn's difficulties was not elaborated, since these difficulties are related to weight gain, nipple lesions, and others. The content analysis of "Clinical Protocols" is presented in Table 2.

Table 2 - Answers of the consultants to each theme of the topic "Clinical Protocols" of the prototype of the application Amamentação Pró - Ribeirao Preto, SP, Brazil, 2019.

\begin{tabular}{lcc}
\hline \multirow{2}{*}{ Clinical protocols } & Consultant A & Consultant B \\
\cline { 2 - 3 } Low maternal milk production & \multicolumn{2}{c}{ Assessment } \\
Theme relevance & Great & Great \\
Content & Great & Great \\
Language & Great & Great \\
Nomenclature & Great & Great \\
Illustrations & Great & Great \\
Topic sequence & Great & Great \\
Contribution to clinical reasoning & Great & Great \\
Font size & Great & Good \\
Colors & Great & Great \\
General appearance & Great & Good \\
\hline
\end{tabular}

Inappropriate weight gain

Theme relevance

Great

Content

Language

Nomenclature

Illustrations

Topic sequence

Contribution to clinical reasoning

Font size

Colors

General appearance

Breast candidiasis

Theme relevance

Content

Language

Nomenclature

Illustrations

Topic sequence

Contribution to clinical reasoning

Font size

Colors

General appearance

\begin{tabular}{|c|c|c|}
\hline \multirow{2}{*}{ Clinical protocols } & Consultant A & Consultant B \\
\hline & \multicolumn{2}{|c|}{ Assessment } \\
\hline \multicolumn{3}{|l|}{ Raynaud's phenomenon } \\
\hline Theme relevance & Great & Great \\
\hline Content & Great & Great \\
\hline Language & Great & Great \\
\hline Nomenclature & Great & Great \\
\hline Illustrations & Great & Bad \\
\hline Topic sequence & Great & Great \\
\hline Contribution to clinical reasoning & Great & Great \\
\hline Font size & Great & Good \\
\hline Colors & Great & Good \\
\hline General appearance & Great & Great \\
\hline \multicolumn{3}{|l|}{ Breast engorgement } \\
\hline Theme relevance & Great & Great \\
\hline Content & Great & Average \\
\hline Language & Great & Average \\
\hline Nomenclature & Great & Average \\
\hline Illustrations & Great & Good \\
\hline Topic sequence & Great & Good \\
\hline Contribution to clinical reasoning & Great & Good \\
\hline Font size & Average & Good \\
\hline Colors & Great & Good \\
\hline General appearance & Good & Good \\
\hline \multicolumn{3}{|l|}{ Mastitis } \\
\hline Theme relevance & Great & Great \\
\hline Content & Great & Average \\
\hline Language & Great & Average \\
\hline Nomenclature & Great & Average \\
\hline Illustrations & Great & Good \\
\hline Topic sequence & Great & Good \\
\hline Contribution to clinical reasoning & Great & Good \\
\hline Font size & Average & Good \\
\hline Colors & Great & Good \\
\hline General appearance & Good & Good \\
\hline \multicolumn{3}{|l|}{ Nipple lesions } \\
\hline Theme relevance & Great & Great \\
\hline Content & Good & Great \\
\hline Language & Great & Great \\
\hline Nomenclature & Good & Great \\
\hline Illustrations & & Bad \\
\hline Topic sequence & Great & Great \\
\hline Contribution to clinical reasoning & Great & Great \\
\hline Font size & Great & Good \\
\hline Colors & Good & Good \\
\hline General appearance & Good & Great \\
\hline
\end{tabular}

Source: elaborated by the authors, 2019. 
In the themes "Breast Candidiasis" and "Raynaud's Phenomenon", there was a disagreement among consultants only on the topic "illustrations", for which one of the consultants attributed the concept "bad" in both themes. As suggestions, the consultants left the following observations for the theme "Breast Candidiasis": adding that the pain is continuous and not only when the baby sucks and the option of dietary treatment; that the fungus is typical of the skin; better define the color as "faint pink, shiny or very opaque in the nipples and/or areolas with or without flaking, possibly containing white scales" and adding the symptom burning and itching; adding history of candidiasis, use of artificial nipples; and for treatment: add use of ointment or gel medication for woman, remove information about the use of gentian violet, due to risk of toxicity; in the theme "Raynaud's Phenomenon", change the term "arteries" for "blood vessels", better define the moment in which "redness" occurs so as not to cause confusion during assessment; add also that paleness right after breastfeeding may be temporary or occur sometime later, the temperature difference between environment and the baby's mouth and the possible unloading of oral tension during breastfeeding with appropriate management; in relation to treatment, add that, before the use of nifedipine, the use of a non-hormonal antiinflammatory such as ibuprofen is recommended and, if there is no improvement, associate it with nifedipine, better explaining the dose of nifedipine so as not to lead to misinterpretation and overdose.

In the themes "Breast engorgement" and "Mastitis", there was disagreement on the topics "content", "language", "nomenclature", and "font size", which received the concept "average" from one of the consultants. In the observations for the theme "breast engorgement", the following information was suggested: infrequent breastfeeding, short duration of breastfeeding, absence of nighttime breastfeeding; application of digital pressure and areolar compression in the preparation of the areola before breastfeeding; better describe the technique for milk extraction, adding the Marmet technique. The use of the expression "manual extraction" instead of "milking" was also suggested.

For the theme "Mastitis", the observations were: include abrupt weaning as a cause; signs and symptoms similar to those of the flu, feeling sick, and myalgia, fever, breast pain, heat, breast rigidity, edema, breast erythema; orientation of not stopping to breastfeed. In use of medication, use associated amoxicillin and clavulanate and remind of clindamycin, as well as adding time of treatment of 10 days. Also for "Mastitis", in the topic "Breast abscess", the consultants suggested to describe the condition as well-circumscribed fluctuation area of the affected, possibly palpable, breast in the clinical exam, and that persistence of fever and other signs, in spite of the use of antibiotics, suggests abscess by itself.

In the theme "nipple lesions", there was a difference only in the item "illustration", for which one of the consultants attributed concept "bad" and the other consultant attributed no concept. The suggestions for the item observation were to review the indication of sunbathing for treatment; insert posteriorized tongue, intense maternal milk flow, increased oral tension as causes for nipple trauma; add orientation for suspension of breastfeeding for recovery of the affected breast until resuming is possible, and use of ointments only during the pause so that there is no damage to the baby's latching, due to making the skin oilier.

\section{DISCUSSION}

The literature includes different software development processes, granting that each team can choose the one which best suits its necessity. In this work, the Prototyping model was chosen due to being an approach that aims at meeting the users' needs, in addition to reducing the time between software creation and its practical application ${ }^{(17)}$. This model has enabled the development of a prototype based on the needs presented by the consultants who formed the development team, making it closer to the reality of these professionals.

The formation of the development team was thought so as to have one representative of each specialty involved in breastfeeding care and from different regions, representing different care realities. Millard, Howard, Gilbert, and Wills ${ }^{(18)}$ emphasize the value of professional and social context in the construction of technology, emphasizing the importance of composition of the team, containing one representative of each specialty, in groups of six to eight participants, with expertise and experience and related to the needs of the final user.

Generally, the consultants assessed positively the visual, functionalities, and the content, and the observations for each topic, assessed with suggestions regarding colors, font, and content, enabled a further enhancement of the prototype before following to the next phase, which will be the development of the application itself from the paper model. This same manner of assessment was used by other authors, taking into account the adaptations to meet the particularities of each study, which also obtained satisfactory results $^{(19-20)}$. This is another advantage of the Prototyping process: repeating the steps of the development process until the needs have been met before putting the software to work, guaranteeing a better quality of the final application $^{(17)}$.

In the assessment of theoretical content referring to the "Clinical Protocol", some consultants disagreed regarding some topics; however, the observations enabled enhancing the content with important information for professionals who are its target public. Due to there being different specialties, one information complements the other, producing a deeper content and, due to being certified by IBLCE, these professionals have an important theoretical and practical background, possibly contributing within their specific areas to the dissemination of more detailed knowledge ${ }^{(21)}$. The professionals' observations will be analyzed based on the literature and subsequently added to the content, contemplating a new phase of this work.

The difficulty in finding in the scientific literature articles which deal with the development of applications on breastfeeding, specifically for professionals, with the function of being a working tool for providing care to mothers and 
babies, shows that the development of this prototype is innovative work.

The use of mHealth technologies in healthcare is encouraged by official bodies, such as the WHO and the $\mathrm{MH}$, but it is also little explored by professionals. It is thus necessary to have a rigorous construction of these technologies, leading to reliability and increasing the chances of them being incorporated into professional routine. The use of mobile technology in breastfeeding deserves to be better explored, since these technologies present potentialities to contribute to professional practice in breastfeeding care, facilitating immediate access to information and being possibly used also as educational tools for professionals and mothers.

\section{CONCLUSION}

The elaborated prototype congregates into a single tool functions of access to information, data storage and help in diagnosing and clinical reasoning related to breastfeeding care. The validation by consultants was positive, despite some points of disagreement. Even so, their contribution has helped to enhance even more the content of the prototype.

Some limitations were faced during the development of this work, such as the distance in relation to the participating professionals. Access to the internet was then used to perform the interviews and assess the prototype, but even so difficulties with connection, access to certain communication applications, and even personal difficulty of some consultants in managing these technologies were present. In spite of these limitations, there was no negative interference in the development of the prototype.

This work is of major importance for professional practice in breastfeeding care as it contributes to the concretization of a tool that enables increasing the knowledge of the professionals, improving quality of care, contributing to best evidence-based practice, optimizing care duration in any setting of professional work by congregating into a single application functions which are useful for the follow-up of mothers and babies.

\section{RESUMO}

Objetivo: Desenvolver e validar um protótipo de aplicativo móvel sobre aleitamento materno para o uso de profissionais de saúde. Método: Estudo metodológico. Para a construção do protótipo, utilizaram-se informações obtidas a partir de entrevistas com seis profissionais de saúde certificados como consultores internacionais em amamentação. Para validação do protótipo construído, foram enviadas a cada um dos profissionais participantes da primeira etapa as telas desenvolvidas e um instrumento adaptado que contemplava avaliação de visual, conteúdo e linguagem. Resultados: A maioria das avaliações atribuíram conceitos "ótimo" ou "bom". Os profissionais participantes também fizeram importantes considerações para enriquecer o conteúdo, especialmente o conteúdo clínico. Conclusão: O protótipo construído recebeu avaliação positiva dos profissionais, atingindo o objetivo proposto. Este trabalho é de grande importância para a prática profissional na assistência à amamentação, pois apresenta uma ferramenta que possibilita melhorar a qualidade da assistência por contribuir para uma prática baseada nas melhores evidências.

\section{DESCRITORES}

Aleitamento Materno; Tecnologia Sem Fio; Telemedicina; Saúde da mulher; Saúde materno-infantil; Tecnologia da Informação.

\section{RESUMEN}

Objetivo: Desarrollar y validar un prototipo de aplicación móvil sobre la lactancia materna para los profesionales de la salud. Método: Estudio metodológico. Para la construcción del prototipo, se utilizó información obtenida de entrevistas con seis profesionales de la salud certificados como consultores internacionales en amamantamiento. Para validar el prototipo construido, se enviaron a cada uno de los profesionales participantes de la primera etapa las pantallas que se desarrollaran y un instrumento adaptado que contemplaba la evaluación visual, de contenido y de lenguaje. Resultados: La mayoría de las evaluaciones asignó los conceptos "óptimo” o "bueno". Los profesionales participantes también hicieron importantes consideraciones para enriquecer el contenido, especialmente el contenido clínico. Conclusión: El prototipo recibió una evaluación positiva por parte de los profesionales, alcanzando el objetivo propuesto. Este trabajo es de gran importancia para la práctica profesional en la asistencia al amamantamiento, una vez que presenta una herramienta que permite mejorar la calidad de la asistencia al contribuir a una práctica basada en las mejores evidencias.

\section{DESCRIPTORES}

Lactancia Materna; Tecnología Inalámbrica; Telemedicina; Salud de la Mujer; Salud Materno-Infantil; Tecnología de la Información.

\section{REFERENCES}

1. Victora CG, Horta BL, Mola CL, Quevedo L, Pinheiro RT, Gigante DP, et al. Association between breastfeeding and intelligence, educational attainment, and income at 30 years of age: a prospective birth cohort study from Brazil. Lancet. 2015;3(4):e199-205. DOI: https://doi.org/10.1016/S2214-109X(15)70002-1.

2. Brasil. Ministério da Saúde. Saúde da criança: Nutrição infantil: aleitamento materno e alimentação complementar. 2nd ed. Brasília: Ministério da Saúde; 2015.

3. Pérez-Escamilla R. Breastfeeding in Brazil: major progress, but still a long way to go. J Pediatr (Rio J). 2017;93(2):107-10. DOI: https:// dx.doi.org/10.1016/j.jped.2016.10.003.

4. Rollins NC, Bhandari N, Hajeebhoy N, Horton S, Lutter CK, Martines JC, et al. Why invest, and what it will take to improve breastfeeding practices? Lancet. 2016;387(10017):491-504. DOI: https://doi.org/10.1016/S0140-6736(15)01044-2.

5. Alvarenga SC, Castro DS, Leite FMC, Garcia TR, Brandão MAG, Primo CC. Critical defining characteristics for nursing diagnosis about ineffective breastfeeding. Rev Bras Enferm. 2018;71(2):314-21. DOI: http://dx.doi.org/10.1590/0034-7167-2016-0549. 
6. Natan MB, Haikin T, Weisel R. Breastfeeding knowledge, attitudes, intentions, and perception of support from educational institutions among nursing students and students from other faculties: a descriptive cross-sectional study. Nurse Educ Today. 2018;68:66-70. DOI: https://doi.org/10.1016/j.nedt.2018.05.026.

7. Fassarella CS, Camerini FG, Henrique DM, Almeida LF, Figueiredo MCB. Evaluation of patient safety culture: comparative study in university hospitals. Rev Esc Enferm USP. 2018;52:e03379. DOI: http://dx.doi.org/10.1590/S1980-220X2017033803379.

8. Moreira ACA, Teixeira FE, Araújo TL, Cavalcante TF, Silva MJ, Cruz ATCT. Software development for nursing care: integrative review. J Nurs UFPE [Internet]. 2016 [cited 2018 June 14];10(6):4942-50. DOI: http://dx.doi.org/10.5205/reuol.8200-71830-3-SM.1006sup201629.

9. Nair P, Bhaskaran H. The emerging interface of healthcare system and mobile communication technologies. Health Technol. 2015;4: 337-43. DOI: https://doi.org/10.1007/s12553-014-0091-x.

10. World Health Organization. eHealth and innovation in women's and children's health: a baseline review: based on the findings of the 2013 survey of ColA countries by the WHO Global Observatory for eHealth [Internet]. Geneva: WHO; 2014 [cited 2018 jun. 16]. Available from: https://apps.who.int/iris/bitstream/handle/10665/111922/9789241564724_eng.pdf?sequence=1 \&isAllowed=y.

11. Coughlin SS. The need for research-tested smartphone applications for promoting breastfeeding. Mhealth. 2016;2(5):18. DOI: https://doi. org/10.21037/mhealth.2016.04.03.

12. Guimarães CMS, Imamura ME, Richter S, Monteiro JCS. Breastfeeding and mHealth technologies: analysis of mobile applications for tablets and smartphones. Rev Eletr Enf. 2018;20:20-8. DOI: https://doi.org/10.5216/ree.v20.48578.

13. Pressman RS. Engenharia de software: uma abordagem profissional. 7th ed. Porto Alegre: AMGH; 2011.

14. International Board of Lactation Consultant Examiners [Internet]. Fairfax: ICLCE; c2019 [cited 2019 Aug 10]. Available from: https://iblce. org/about-iblce/.

15. International Lactation Consultant Association [internet]. Raleigh: International Lactation Consultant Association; 2018 [cited 2018 July 01]. Available from: https://www.ilca.org/why-ibclc/falc.

16. Fonseca LMM, Leite AM, Mello DF, Dalri MCB, Scochi CGS. Semiotics and semiology of the preterm newborn: evaluation of an educational software application. Acta Paul Enferm. 2008;21(4):543-8. DOI: http://dx.doi.org/10.1590/S0103-21002008000400002.

17. Gordon JR, Gordon SR. Sistemas de informação: uma abordagem gerencial. Rio de Janeiro: LTC; 2006.

18. Millard D, Howard Y, Gilbert L, Wills G. Co-design and co-deployment methodologies for innovative m-learning systems. In: Goh TT, editor. Multiplatform e-learning systems and technologies: mobile devices for ubiquitous ICT-Based Education. Hershey: IGI Global; 2009.

19. Vasconcelos MGL, Góes FSN, Fonseca LMM, Ribeiro LM, Scochi CGS. User assessment of a digital learning environment. Acta Paul Enferm. 2013;26(1):36-41. DOI: http://dx.doi.org/10.1590/S0103-21002013000100007.

20. Góes FSN, Fonseca LMM, Furtado MCC, Leite AM, Scochi CGS. Evaluation of the virtual learning object "Diagnostic reasoning in nursing applied to preterm newborns". Rev Latino-Am Enfermagem. 2011;19(4):894-901. DOI: http://dx.doi.org/10.1590/S010411692011000400007.

21. Haase B, Brennam E, Wagner CL. Effectiveness of the IBCLC: have we made an impact on the care of breastfeeding families over the past decade? J Hum Lact. 2019;35(3):441-52. DOI: https://doi.org/10.1177/0890334419851805.

\section{Financial support}

This study was supported by Coordenação de Aperfeiçoamento de Pessoal de Nível Superior - Brasil (CAPES) - Funding code 001. 